\title{
Desafios para a inclusão digital no Brasil
}

\author{
Fernando Augusto Mansor De Mattos
}

Professor e Pesquisador no Programa de Pós-Graduação em Ciência da Informação da PUC de Campinas. Professor também no Centro de Economia e Administração (CEA) da PUC de Campinas. Mestre e Doutor pelo Instituto de Economia (IE) da UNICAMP. E-mail: fermatt@uol.com.br

\section{Gleison José do Nascimento Chagas}

Graduando do curso de Ciência da Informação na PUC de Campinas. Aluno de Iniciação Científica, com bolsa da Reitoria da PUC Campinas (FAPIC Reitoria, equivalente à da bolsa do CNPQ), desenvolvendo o trabalho de pesquisa intitulado "Indicadores de Exclusão Digital no Brasil", vinculado ao projeto de pesquisa do professor, denominado "Economia Política da Informação".

O objetivo deste artigo é apontar alguns dos principais limites e possibilidades que devem nortear as políticas de inclusão digital no Brasil. A primeira parte do artigo mostra que o surgimento das novas Tecnologias da Informação e da Comunicação (TIC's) tem ampliado o caráter assimétrico e excludente do atual processo de globalização econômica. A segunda parte do artigo descreve a elevada desigualdade econômica e social brasileira, a qual se expressa também em acentuada exclusão digital.A terceira parte destaca os limites e condicionantes das políticas públicas de inclusão digital no Brasil, considerando-se as peculiaridades sociais e econômicas enumeradas nas partes iniciais do artigo e também as especificidades das tecnologias envolvidas. Nas conclusões, são destacadas as dificuldades de inclusão digital em uma sociedade já acentuadamente desigual como a brasileira. 
Palavras-chave: Inclusão digital; Exclusão digital; Globalização econômica; Exclusão social no Brasil; Políticas públicas.

\section{Challenges for digital inclusion in Brazil.}

The aim of this paper is to highlight some of the main limits and possibilities that should conduct public policies for digital inclusion in Brazil. In the first part of the article, we show that the appearance of the new Information and Communication Technologies has been increasing the asymmetries and exclusion that characterize the present process of economic globalization. In the second part, we describe the huge economic and social inequality in Brazil, which is also expressed as a remarkable digital divide. The third part of the paper highlights the limits and possibilities involved in the elaboration of public policies for digital inclusion in Brazil, considering not only the social and the economic peculiarities analyzed previously in the article, but also the specificities of the technology involved in these policies to attenuate the digital divide.

Keywords: Digital inclusion; Digital divide; Economic globalization; Social exclusion In Brazil; Public policies.

Recebido em 30.04.2007 Aceito em 06.03.2008

\section{Apresentação}

O objetivo do artigo não é avaliar políticas específicas de inclusão digital, mas discutir o conceito e a problemática da inclusão digital e, a partir disso, destacar a importância da elaboração de políticas públicas de inclusão digital e delimitar seus aspectos mais gerais, necessários para promover melhor inserção social em um país profundamente desigual como o Brasil. É por isso que, na primeira parte do artigo, trata-se de descrever a enorme desigualdade existente na sociedade brasileira, de forma a destacar como essas peculiaridades brasileiras devem ser levadas em conta no desenho das políticas públicas de inclusão digital no país.

A primeira parte do artigo chama atenção para o fato de que a implementação das Tecnologias da Informação e da Comunicação (TIC's) ocorre em um contexto marcado por acentuados e crescentes processos de exclusão social e de geração de assimetrias, decorrentes das características econômicas e geopolíticas do atual momento vivido pela Globalização Econômica capitalista. 
Na segunda parte do artigo, são apresentados alguns dados que descrevem a histórica desigualdade sócio-econômica brasileira, bem como o grau de exclusão digital atualmente vigente no país. São feitos alguns comentários críticos a respeito da imprecisão de alguns indicadores que se destinam a medir a exclusão digital. Apregoa-se a necessidade da mesma ser analisada não apenas em termos quantitativos, mas também qualitativos.

Em uma terceira parte, são discutidos os marcos gerais em que se devem basear as políticas de inclusão digital em um país com as peculiaridades apontadas nas duas primeiras partes do capítulo, levando em conta também as especificidades das tecnologias envolvidas.

Nas conclusões, são destacadas as especificidades da sociedade brasileira e as dificuldades de inclusão digital em uma sociedade já acentuadamente desigual. São propostas também novas formas de se avaliar a magnitude da exclusão digital no Brasil, ressaltando a necessidade de o Estado brasileiro formular e implementar políticas públicas para ampliar o contingente de "infoincluídos" no país.

Assimetrias da globalização atual e ascensão das tecnologias da informação e da comunicação

Estudos sobre história do desenvolvimento econômico revelam a tendência à desigualdade gerada pelo processo de acumulação capitalista. A não ser em raros períodos de exceção, como os chamados Anos Dourados do século XX (1945-1973), o Capitalismo caracterizou-se pela permanente criação e recriação de desigualdades e de assimetrias de todo tipo: entre países, entre classes sociais dentro dos países e até mesmo entre diferentes segmentos capitalistas dentro dos países.

Estatísticas sobre a desigualdade mundial de renda podem ser recolhidas em estudos da $O C D E^{1}$, que revelam, entre outros dados, que a participação dos trabalhadores desempregados dos países do chamado Terceiro Mundo no total de trabalhadores desempregados no mundo aumentou entre 1990 e 2001, assim como aumentou a diferença entre a renda per capita dos países do chamado G7 (os sete países mais ricos do mundo) e a renda per capita dos países mais pobres, situação também revelada por publicação recente do $\mathrm{FMI}^{2}$. Esses dados desmistificam um pouco as supostas excelências da chamada "nova economia", marcada, no campo tecnológico, pela ascensão das tecnologias da Informação e da Comunicação e, no campo ideológico, pela hegemonia do pensamento neoliberal ${ }^{3}$.

\footnotetext{
Cf., por exemplo, OCDE ECONOMIC OUTLOOK (2002).

Cf. IMF, WORLD ECONOMIC OUTLOOK (2007).

Neoliberalismo pode ser definido como um conjunto de medidas de política econômica que começaram a ser implementadas notadamente a partir do final dos anos 1970 (na Grã-Bretanha, com Margareth Thatcher) e início dos anos 1980 (nos EUA, com Ronald Reagan), mas que depois se espalhou para outros países. O neoliberalismo pode ser considerado uma reação à hegemonia das políticas social-democratas que haviam sido adotadas no pós-segunda guerra. De modo geral, pode-se afirmar que as medidas de caráter neoliberal destinam-se a remover todas as formas de intervenção e controle dos Estados Nacionais em todos os mercados, destacando-se o mercado financeiro e os mercados de trabalho. $O$ objetivo das políticas neoliberais é sempre o de facilitar e incentivar os movimentos de capitais entre países e entre mercados. A idéia subjacente a essas medidas é a de que o "livre funcionamento das forças de mercado" permite uma alocação mais eficiente dos recursos econômicos "escassos", com um resultado final que favorece - segundo a ideologia neoliberal - o conjunto da sociedade.
} 
Tremblay (2005) ressalta que a chamada "nova economia" é caracterizada pela chamada Sociedade da Informação (SI), mas reitera que não há elementos para supor que estejam corretos os autores que apregoam que o momento atual represente uma mudança radical com modelos sociais precedentes. O autor discorda de autores que defendem a idéia segundo a qual o atual cenário econômico internacional tenha promovido uma ruptura com a sociedade industrial e que esta ruptura receberia o nome de Sociedade Informacional ou, como prefere Castells, seria denominada de era do "Capitalismo Informacional". Tremblay (2005) não nega que estejam em curso mudanças importantes no processo de produção capitalista, mas ressalta que essas mudanças não têm conduzido a uma ruptura com o anterior modelo capitalista, mas sim a uma continuidade, sob novas bases, do modelo de desenvolvimento industrial fundado na inovação científica e tecnológica que tem caracterizado o capitalismo dos países desenvolvidos desde pelo menos o final do século XIX. Em certa passagem, Tremblay (2005) concorda com interpretação de Garnham (1998), que nega que seja uma "novidade" o atual momento histórico caracterizado pelas TIC's, pois elas seriam, segundo Garnham, apenas mais uma manifestação de avanço tecnológico capitalista em busca de novas fronteiras de acumulação de capital. Ao concordar com Garnham, Tremblay está concordando que o padrão de acumulação capitalista atual não representa uma mudança em relação ao do período da "sociedade industrial" (ou seja, do auge do fordismo) em um aspecto fundamental: o assalariamento é a norma da relação de trabalho, hoje como antes.

Proenza (2003) salienta que o próprio desenvolvimento das TIC, ocorrido sob o processo de globalização atual, tende também a criar novos elementos que contribuem para ampliar as desigualdades econômicas. 0 autor apresenta quadros que ilustram seus argumentos. Em primeiro lugar, ele mostra dados que revelam uma acentuada diferença de inclusão digital entre os países. No referido trabalho, pode-se notar que nas regiões mais pobres do planeta existem baixos níveis de conexão à internet. Por outro lado, nos países mais desenvolvidos existem expressivos níveis de conexão à internet, a menos de algumas diferenças derivadas de fatores culturais que conduzem as respectivas populações a níveis variados de interesse pelo uso de novas tecnologias.

Proenza (2003) destaca também que há uma correspondência entre esses indicadores e os indicadores de níveis e de distribuição de renda. Ou seja, os países com renda per capita menor e/ou com renda mais concentrada são justamente aqueles que ostentam os mais eloqüentes indicadores de infoexclusão.

Ramonet (1998) sublinha que os notáveis índices de desigualdade refletem-se também na distribuição mundial do acesso digital. Ramonet (1998) salienta, ainda, que têm surgido novas desigualdades geradas pelo próprio desenvolvimento acelerado da Internet. Segundo o autor, a expansão da Internet tem gerado uma nova desigualdade, denominada por ele de "inforricos" e "infopobres", destacando que, em primeiro lugar, sempre apenas uma pequena minoria dispõe de computador pessoal, 
mesmo nos países ricos. Ademais, lembra Ramonet (1998), a infraestrutura em telefonia e os aspectos cognitivos (no mínimo, a alfabetização, cujos índices são bastante diferenciados entre os diversos países do mundo) contam de maneira decisiva para a definição da clivagem entre "inforricos" e "infopobres". Na seguinte passagem, Ramonet (1998) deixa claro seu ponto de vista:

não há dúvida de que, com a Internet - mídia, daqui em diante, tão banal quanto o telefone - entramos em uma nova era da comunicação. Muitos estimam, com certa ingenuidade, que o volume cada vez maior de comunicação fará reinar, nas nossas sociedades, uma harmonia crescente. Ledo engano. A comunicação, em si, não constitui um progresso social. E ainda menos quando é controlada pelas grandes firmas comerciais da multimídia. Ou quando contribui para aprofundar as diferenças e as desigualdades entre cidadãos do mesmo país, ou habitantes do mesmo planeta (RAMONET, 1998, p.145).

Os efeitos assimétricos do atual processo de globalização, provocados pelas novas Tecnologias da Informação e da Comunicação (TIC's), foram também destacados por Riccardo Petrella ${ }^{4}$ :

mais do que uma nova ordem mundial fundada sobre os Estados-Nações em concorrência (...) assistimos à emergência de um arquipélago de cidades/regiões ricas, hiperdesenvolvidas nos planos tecnológico, industrial e financeiro, no oceano de uma humanidade cada vez mais pobre. Graças, entre outras coisas, às novas tecnologias da informação, da comunicação e do transporte, essas cidades/regiões estão ativamente ligadas umas às outras por intermédio de empresas multinacionais e transnacionais, elas mesmas interconectadas no seio dos conglomerados financeiros e industriais mundiais.

Essa nova realidade descrita pelos autores acima mencionados define um ambiente de concorrência internacional crescentemente acirrada sob a atual forma de globalização econômica, e colocam desafios para países mais pobres e para suas respectivas populações em termos de inserção não apenas no mundo globalizado, mas também no domínio efetivo das tecnologias da informação e da comunicação. Em uma palavra: desafios para a inclusão digital.

No caso específico brasileiro, há dificuldades que precisam ser mencionadas. Em primeiro lugar, a crise econômica dos últimos anos, além de ter impedido a ascensão social de uma parte significativa da população, deixou dificuldades adicionais para que o Estado pudesse investir efetivamente na melhoria da Educação Básica do país. Tal situação tem consolidado e ampliando as já enormes diferenças existentes

4 PeTRELLA, R. (1993), citado também por BOLAÑo (2005). 
entre as pessoas em termos de educação formal, fazendo do fator cognitivo outro elemento que limita as possibilidades de se construir no país um projeto de efetiva ampliação da inclusão digital. Ou seja, a capacidade de compreensão e a possibilidade de se utilizar efetivamente todas as potencialidades oferecidas pelas Tecnologias de Informação e Comunicação são bastante diferenciadas na população brasileira, dado o alto grau de desigualdade na educação formal das pessoas ${ }^{5}$. Esta diferença (cognitiva) não é captada pelos indicadores tradicionais de inclusão digital (percentual de acesso a computadores, e percentual desses que são conectados à internet), fazendo crer que a evolução dos dados de ampliação da inclusão digital no Brasil na verdade não retratam uma realidade tão positiva como parece sugerir a fria análise das estatísticas. Ou seja, não se pode captar - pela forma como as estatísticas de inclusão digital têm sido reveladas ${ }^{6}$ - se de fato a ampliação do número de pessoas conectadas à internet significa que essas pessoas

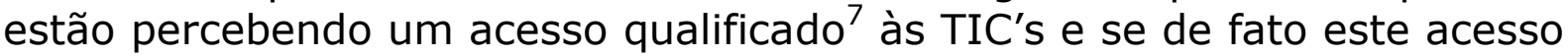
tem promovido uma melhoria significativa na qualidade de vida dessas pessoas.

Além disso, em um país como o Brasil, as enormes diferenças entre as áreas rurais e as urbanas representam um complicador adicional para que se tenha uma homogeneidade digital no país. As características do processo de industrialização brasileira permitiram a convivência de estruturas produtivas de diferenciadíssimos graus de produtividade, as quais, por sua vez, apresentam diferenciadas dificuldades de acesso às TIC's, o que se expressa, em um segundo momento, em desiguais possibilidades de acessar dados, informações e atingir mercados para seus produtos, promovendo, por sua vez, heterogêneos resultados em termos de estratégias competitivas empresariais, conforme a capacidade de cada empresa usufruir das TIC's como um mecanismo para incrementar sua respectiva participação nos mercados.

Por fim, deve-se lembrar que os custos de acesso à internet (pagamento de linha e/ou de provedores de acesso) excluem certos setores produtivos, algumas empresas de pequeno porte e também muitas pessoas do uso das TIC's, acentuando as diferenças geradas pelas oportunidades de mercado para as empresas e pelas oportunidades profissionais entre as pessoas.

5 AUN e ANGELO (2007) destacam que a Educação representa fator decisivo para combater o "apartheid digital", por dotar os cidadãos de capacidade cognitiva para transformar informação em conhecimento.

6 Esse componente cognitivo da inclusão digital não tem sido bem dimensionado pela literatura brasileira e nem pela estrangeira que discute o tema; não se pode deixar de reconhecer, entretanto, que se trata de um problema metodológico de difícil solução. No entanto, pode-se supor que, no caso brasileiro, dadas as características históricas do processo de industrialização brasileira e dada a situação falimentar da Educação Básica Formal do Brasil, exista uma distorção ainda maior entre a realidade concreta e aquela descrita pelos indicadores tradicionais de inclusão/exclusão digital, como os divulgados pelo IBGE.

7 Entende-se por acesso qualificado um acesso de boa qualidade técnica, baixo custo e, fundamentalmente, que $o$ acesso à internet seja feito por um indivíduo que tenha capacidade cognitiva para compreender o conteúdo acessado e que sua interação com a internet possa lhe conferir melhoria em seu padrão de vida, o que inclui melhoria de sua inserção profissional no mercado de trabalho, maior acesso à cultura, à cidadania etc. 


\section{Concentração de renda e exclusão digital no Brasil}

A partir da segunda metade dos anos 1990, a sociedade brasileira assistiu a uma notável expansão do uso da internet (FGV, 2001) ${ }^{8}$. Essa nova realidade trouxe à tona uma necessidade de reflexão a respeito dos condicionantes desse fenômeno, bem como de seus resultados sobre a sociabilidade e sobre as estratégias empresariais. A tão decantada inclusão digital ainda está por ser mais bem avaliada, tanto quantitativamente como também qualitativamente. Algumas perguntas surgem, neste contexto: (a) o que de fato vem a ser "inclusão digital?"; (b) em que medida e em que condições a chamada inclusão digital pode se transformar em um processo de inclusão social, em especial em uma sociedade como a brasileira, marcada por fortes desigualdades de renda e de riqueza, tanto em termos pessoais quanto também em termos regionais?

Antes de discutir os critérios e os indicadores de inclusão digital propriamente ditos, é interessante apresentar um breve painel descritivo do perfil distributivo brasileiro, como uma forma de tentar descrever o cerne dos problemas socioeconômicos do país. A seguir, serão analisados os indicadores de expansão da Internet no Brasil e em que medida este fenômeno vem sendo delimitado pelas próprias condições sociais e econômicas do país.

A desigualdade na distribuição da renda é certamente um fator distintivo da realidade brasileira em comparação aos demais países do mundo ${ }^{9}$. Esse fenômeno pode ser medido tanto pela distribuição funcional da renda (ou seja, repartição da renda nacional entre salários e lucros), quanto pela distribuição pessoal da renda (distribuição da renda pessoal do trabalho segundo estratos da pirâmide distributiva brasileira).

A tabela 1 revela que a concentração funcional da renda no Brasil é elevadíssima e aumentou entre 1990 e 1993 10. A elevada desigualdade brasileira tem causas histórico-estruturais variadas, que se originam desde a época da colonização, passando pela era da economia primárioexportadora e adentrando o longo período de industrialização, entre os anos 1930 e 1980. Na década de 1980, a economia enfrentou a chamada

8 Dados mais recentes, divulgados pelo Internet World Series (2007), revelam que, entre 2000 e dezembro de 2007, aumentou 752\% o acesso e uso da Internet no Brasil.

9 Não se trata de afirmar que o Brasil seja o único país com acentuada desigualdade de renda e nem mesmo de afirmar que somente no Brasil esteja ocorrendo, nas décadas mais recentes, um processo de piora do perfil distributivo. Dados do FMI (IMF, 2007), notadamente no capítulo 4 do referido estudo (capítulo intitulado "Globalization and Inequality"), mostra que houve uma ampliação da desigualdade de renda entre países nas últimas décadas, bem como uma ampliação da desigualdade de renda dentro da maior parte dos países, tomando-se os dados segundo os quintis (extratos de 20\%) da pirâmide distributiva. Da mesma forma, o World Development Report de 2006 (WORLD BANK, 2006) revela ter havido, nas décadas mais recentes, uma ampliação das desigualdades de renda dentro dos países e entre eles.

10 A distribuição funcional da renda representa a repartição da renda nacional entre lucros (na tabela 1 descrita, grosso modo, como "excedente operacional bruto") e salários (ou, em um sentido mais amplo, remuneração dos empregados, que inclui a soma dos rendimentos das pessoas que vivem do próprio trabalho, ou seja, os assalariados (empregados) e os trabalhadores autônomos - ver tabela 1). $O$ caso brasileiro é um dos mais marcantes em termos de concentração de renda em favor do capital. Essa concentração funcional da renda se desdobra, invariavelmente, em alta concentração pessoal da renda do trabalho (cf. MATTOS, 1995). Tanto no caso da distribuição funcional, quanto no da distribuição pessoal da renda, o Brasil é um dos países cuja renda está entre as mais concentradas do mundo (cf. DIEESE, 2001a; p. 37). 
"década perdida", quando a economia brasileira teve uma forte redução do seu ritmo de crescimento econômico, especialmente se comparado ao que ocorrera nas décadas anteriores. Os anos 1990 representaram a pior década do século $X X$ em termos de crescimento econômico e de desenvolvimento social. Tal situação de grave crise econômica teve imediato rebatimento sobre o mercado de trabalho brasileiro (MATTOS, 1994), que enfrentou aumento do desemprego, retração do ritmo de geração de postos de trabalho, ampliação da informalidade, redução dos salários reais e ampliação da insegurança dos detentores dos postos de trabalho a partir dos anos 1980. Tal mudança de realidade econômica e social representou uma ruptura da trajetória de estruturação do mercado de trabalho brasileiro, marcada pela expansão do peso do emprego formal (emprego assalariado com carteira de trabalho assinada) e do emprego industrial no conjunto das ocupações do mercado de trabalho brasileiro que vinha ocorrendo desde pelo menos a década de 1940 (POCHMANN, 1999; 2001). Aquele período de expansão da economia, ocorrido a partir dos anos 1930, porém, redundara em uma piora do perfil de distribuição da renda ${ }^{11}$ (conforme mostram os dados da tabela 2 ). Naquele período, a piora da distribuição de renda deveu-se ao fato de que os rendimentos das pessoas mais ricas subiram mais do que os rendimentos das mais pobres. Dessa forma, o desconforto causado pela ampliação da desigualdade pôde ser mitigado pelo fato de que, embora crescendo menos do que os rendimentos dos mais ricos, os rendimentos das pessoas mais pobres estavam também em ascensão e era possível a eles perceber uma melhoria de padrão de vida. De qualquer forma, a renda média nacional crescia e era possível, para amplas camadas da população, experimentar um momento de ascensão social.

A partir dos anos 1980, porém, o cenário econômico piora, pois, ao contrário do que ocorrera durante o período da industrialização, a renda fica praticamente estagnada e a distribuição da renda continua a se deteriorar, mas, a partir desse momento, com um agravante: a concentração da renda ocorre com queda dos rendimentos das pessoas de mais baixa renda, enquanto as pessoas de rendas médias e altas conseguem se proteger contra a queda de rendimentos reais provocada pela inflação. Nesse contexto de estagnação econômica e alta inflação,

11 A tabela 2 mostra que a parcela da renda nacional apropriada pelos trabalhadores mais pobres cai entre 1960 e 1980, ao mesmo tempo em que as parcelas apropriadas respectivamente pelo $1 \%, 5 \%$ e $10 \%$ mais ricos aumentam, fazendo com que o índice de Gini aumente expressivamente no período. O índice de Gini é um indicador de desigualdade bastante usual nos estudos econômicos, que varia de zero a um, sendo que o hipotético zero representa completa igualdade e o hipotético um representa total desigualdade. Ou seja, se, teoricamente, apenas uma pessoa de toda a sociedade se apropriasse de toda a renda, o índice seria igual a um, representando a completa desigualdade; por outro lado, se cada pessoa se apropriasse de uma mesma renda, o índice seria igual a zero, o que representaria uma situação de completa igualdade. $O$ índice de Gini também é conhecido como Coeficiente de Gini e é geralmente utilizado para avaliar concentração de renda, mas também pode ser utilizado para avaliar por exemplo concentração da propriedade fundiária ou a produção industrial por setores. Em estudos de séries históricas de dados estatísticos, o Coeficiente de Gini se altera quando se altera o perfil de distribuição dos dados. Quando o índice se aproxima de um significa que a amostra de dados em questão está refletindo um movimento em direção a uma maior desigualdade. Por outro lado, quando o índice se aproxima de zero, significa que a amostra dos dados em análise está se modificando em direção a uma situação de maior equanimidade. Vale destacar que, normalmente, os índices de Gini se alteram pouco ao longo do tempo, pois fatores distributivos não se alteram rapidamente, pois depende de fatores estruturais e históricos que não estão sujeitos a modificações rápidas e expressivas. 
ampliou-se o contingente de desempregados e de trabalhadores autônomos e também de trabalhadores assalariados sem carteira assinada cujos rendimentos, invariavelmente, eram baixos; dessa maneira, o aumento estatístico da desigualdade veio acompanhado de insegurança social crescente e da sensação de impotência diante de um quadro econômico que parecia deteriorar-se continuamente.

É nesse cenário socioeconômico que surgem as novas TIC's e que se amplia o seu uso. O ambiente social e econômico herdado dos anos de perda de dinamismo econômico deixa esse legado para a geração de brasileiros que cresce convivendo (ou não...) com a existência das novas TIC's, o que dificulta a consolidação dos possíveis efeitos positivos das políticas de inclusão digital sobre o padrão de vida material dessas pessoas e sobre sua qualificação profissional. A despeito da tênue melhoria do perfil distributivo brasileiro nos anos mais recentes (segundo dados divulgados pelo IPEA), a gravidade e o caráter estrutural dos problemas de inclusão social no país ainda se colocam da mesma maneira que se colocavam no início e meados dos anos 1990, quando surgiram as TIC's no Brasil. Da mesma forma, nesse cenário econômico deteriorado colocam-se dificuldades materiais para que de fato sejam praticadas políticas públicas de inclusão digital no Brasil.

A tabela 1 ilustra o quadro de deterioração econômica, ao revelar que, nos anos 1990, a participação dos lucros na renda nacional aumentou, o que significa que ocorreu uma piora da distribuição funcional da renda no país.

TABELA 1 - Composição do PIB no Brasil no período 1990-2003 (em participação \% no total)

\begin{tabular}{ccccc}
\hline Anos & $\begin{array}{c}\text { Excedente } \\
\text { Operacional } \\
\text { Bruto }\end{array}$ & $\begin{array}{c}\text { Impostos } \\
\text { sobre } \\
\text { Produção } \\
\text { e Importação }\end{array}$ & $\begin{array}{c}\text { Rendimentos } \\
\text { do Trabalho } \\
\text { (Empreg.+ } \\
\text { Aut.) }\end{array}$ & TOTAL \\
\hline 1990 & 32,6 & 15,1 & 52,3 & 100 \\
1991 & 38,5 & 12,9 & 48,7 & 100 \\
1992 & 38,0 & 12,2 & 49,8 & 100 \\
1993 & 35,4 & 13,2 & 51,4 & 100 \\
1994 & 38,4 & 15,8 & 45,8 & 100 \\
1995 & 40,3 & 15,6 & 44,2 & 100 \\
1996 & 41,0 & 14,8 & 44,2 & 100 \\
1997 & 42,8 & 14,2 & 43,0 & 100 \\
1998 & 41,6 & 14,0 & 44,5 & 100 \\
1999 & 40,5 & 15,6 & 43,8 & 100 \\
2000 & 40,6 & 16,2 & 43,2 & 100 \\
2001 & 40,9 & 17,0 & 42,1 & 100 \\
2002 & 41,9 & 17,4 & 40,7 & 100 \\
2003 & 43,0 & 16,9 & 40,1 & 100 \\
\hline
\end{tabular}

Fonte: Elaboração própria a partir dos dados do IBGE de Contas Nacionais 1990-2003. 
TABELA 2 - Distribuição de rendimento do trabalho e Índice de Gini Brasil 1960/70/80

\begin{tabular}{lccc}
\hline & 1960 & 1970 & 1980 \\
\hline $20 \%$ mais pobres & 3,9 & 3,4 & 2,8 \\
$50 \%$ mais pobres & 17,4 & 14,9 & 12,6 \\
$10 \%$ mais ricos & 39,6 & 46,7 & 50,9 \\
$5 \%$ mais ricos & 28,3 & 34,1 & 37,9 \\
$1 \%$ mais rico & 11,9 & 14,7 & 16,9 \\
& & & \\
Indice de Gini & 0,49 & 0,56 & 0,59 \\
\hline
\end{tabular}

Fonte: IBGE, 2004.

Ao longo do século $\mathrm{XX}$, a economia brasileira alternou momentos de expansão com momentos de retração ou estagnação da atividade econômica, mas sempre esses movimentos cíclicos da economia brasileira vieram acompanhados de deterioração do perfil de distribuição de renda e de riqueza na sociedade brasileira. Outra marca da economia brasileira é a sua acentuada concentração regional da renda. A despeito de ter ocorrido, ao longo dos anos 1970 e 1980, uma diminuição da concentração regional da renda (MATTOS, 1996), a economia brasileira ainda é marcada por elevado grau de desigualdade regional, conforme mostra a tabela 3, na qual se pode perceber que mais de $50 \%$ da renda nacional concentra-se nos três estados mais ricos da federação. Interessante notar, na mesma tabela, que a contribuição percentual de cada estado da federação para o seleto grupo dos chamados "incluídos digitais" do Brasil, segundo dados retirados da PNAD de 2005, reflete quase identicamente a contribuição de cada estado para a renda nacional. Tal "coincidência" sugere que, na verdade, a inclusão digital, medida desta forma simples, ou seja, segundo os dados declarados pelo IBGE $^{12}$, na melhor das hipóteses ${ }^{13}$ apenas referenda e repete o grau de desigualdade regional e pessoal da renda no Brasil.

A tabela 4, por sua vez, mostra o grau de "inclusão digital" de cada estado da federação. A tabela revela, antes de tudo, que, em 2005, apenas $21 \%$ dos brasileiros com dez anos ou mais de idade utilizaram a internet no período de referência dos últimos três meses antes da pesquisa da PNAD - ou seja, apenas uma parcela minoritária da população brasileira pode ser considerada como "digitalmente incluída", de acordo com os critérios do IBGE. Esse número (21\%), porém, tomado isoladamente e sem maiores considerações analíticas, esconde a enorme desigualdade regional brasileira em termos de inclusão digital. Analisandose os dados de inclusão digital para cada um dos estados da Federação, constata-se uma significativa diferenciação regional no país, conforme mostram os dados da tabela 4.

12 O IBGE, nas pesquisas anuais feitas para as PNAD's, considera como digitalmente incluído o indivíduo que tenha acessado a internet pelo menos uma vez nos últimos três meses anteriores à pesquisa.

13 Muitos autores, como, por exemplo, SILVEIRA (2001) e MATTOS (2003), destacam que a exclusão digital chega até mesmo, em muitos casos, a ampliar o grau de desigualdade social existente em certas sociedades. 
TABELA 3 - Participação de cada estado na renda nacional e na inclusão digital - Brasil 2005

\begin{tabular}{|c|c|c|}
\hline $\begin{array}{c}\text { Estados } \\
\text { da } \\
\text { Federação }\end{array}$ & $\begin{array}{c}\text { Participação do estado } \\
\text { na renda nacional } \\
(\mathrm{em} \%)\end{array}$ & $\begin{array}{l}\text { Contribuição do estado } \\
\text { no total de incluídos } \\
\text { digitais do Brasil (em \%) }\end{array}$ \\
\hline São Paulo & 31,8 & 31,9 \\
\hline Rio de Janeiro & 12,2 & 11,0 \\
\hline Minas Gerais & 9,3 & 9,5 \\
\hline Rio Grande do Sul & 8,2 & 6,7 \\
\hline Paraná & 6,4 & 6,9 \\
\hline Bahia & 4,7 & 4,5 \\
\hline Santa Catarina & 4,0 & 4,6 \\
\hline Pernambuco & 2,7 & 2,9 \\
\hline Goiás & 2,4 & 2,7 \\
\hline Distrito Federal & 2,4 & 2,5 \\
\hline Espírito Santo & 1,9 & 2,1 \\
\hline Pará & 1,9 & 1,9 \\
\hline Ceará & 1,8 & 2,7 \\
\hline Amazonas & 1,8 & 0,8 \\
\hline Mato Grosso & 1,5 & 1,3 \\
\hline Mato Grosso do Sul & 1,2 & 1,3 \\
\hline Paraíba & 0,9 & 1,2 \\
\hline Maranhão & 0,9 & 1,2 \\
\hline Rio Grande do Norte & 0,9 & 1,0 \\
\hline Sergipe & 0,8 & 0,6 \\
\hline Alagoas & 0,7 & 0,5 \\
\hline Rondônia & 0,5 & 0,5 \\
\hline Piauí & 0,5 & 0,7 \\
\hline Tocantins & 0,3 & 0,4 \\
\hline Amapá & 0,2 & 0,3 \\
\hline Acre & 0,2 & 0,2 \\
\hline Roraima & 0,1 & 0,1 \\
\hline
\end{tabular}

Fonte: IBGE. Dados de inclusão digital: PNAD, 2005. Elaboração própria.

Dados de PIB estadual: Contas Regionais do Brasil (IBGE), 2004.

Elaboração própria.

$(*)$ as somas das respectivas colunas podem diferir um pouco de 100 por causa de arredondamentos. 
TABELA 4 - Pessoas com 10 anos ou mais de idade, por utilização da Internet (*) Por unidades da Federação - Brasil; 2005

\begin{tabular}{|c|c|c|c|}
\hline $\begin{array}{l}\text { Unidades da } \\
\text { Federação }\end{array}$ & $\begin{array}{c}\text { População com } \\
10 \text { anos ou mais de } \\
\text { idade }\end{array}$ & $\begin{array}{l}\text { utilizaram internet } \\
\text { (valores absolutos) }\end{array}$ & $\begin{array}{l}\text { percentual em relação } \\
\text { ao total da população }\end{array}$ \\
\hline Brasil & 152740402 & 32129971 & 21,0 \\
\hline Distrito Federal & 1921648 & 791368 & 41,2 \\
\hline São Paulo & 34328468 & 10254783 & 29,9 \\
\hline Santa Catarina & 4973678 & 1468159 & 29,5 \\
\hline Rio de Janeiro & 13243763 & 3529820 & 26,7 \\
\hline Paraná & 8562890 & 2220608 & 25,9 \\
\hline Espírito Santo & 2822307 & 669231 & 23,7 \\
\hline Rio Grande do Sul & 9248381 & 2148575 & 23,2 \\
\hline Mato Grosso do Sul & 1869408 & 421475 & 22,5 \\
\hline Amapá & 451171 & 90129 & 20,0 \\
\hline Goiás & 4639018 & 875091 & 18,9 \\
\hline Minas Gerais & 16180591 & 3045476 & 18,8 \\
\hline Mato Grosso & 2316442 & 425145 & 18,4 \\
\hline Tocantins & 1048370 & 150256 & 14,3 \\
\hline Pernambuco & 6848395 & 933929 & 13,6 \\
\hline Rondônia & 1242535 & 168177 & 13,5 \\
\hline Roraima & 303283 & 40990 & 13,5 \\
\hline Acre & 484688 & 64192 & 13,2 \\
\hline Ceará & 6577057 & 851567 & 12,9 \\
\hline Bahia & 11199568 & 1445236 & 12,9 \\
\hline Rio Grande do Norte & 2445303 & 315249 & 12,9 \\
\hline Sergipe & 1623881 & 204136 & 12,6 \\
\hline Paraíba & 2937731 & 363383 & 12,4 \\
\hline Pará & 5419911 & 592590 & 10,9 \\
\hline Amazonas & 2471024 & 259399 & 10,5 \\
\hline Piauí & 2434208 & 252922 & 10,4 \\
\hline Maranhão & 4766806 & 367853 & 7,7 \\
\hline Alagoas & 2379877 & 180232 & 7,6 \\
\hline
\end{tabular}

Fonte: IBGE, Diretoria de Pesquisas. Pesquisa Nacional por Amostra de Domicílios (PNAD), 2005.

$(*)$ no período de referência dos últimos 3 meses.

Os dados da tabela 4 revelam que, no Distrito Federal, cerca de $41 \%$ das pessoas haviam acessado a internet no período de referência. Além do DF, é nos estados mais ricos e mais urbanizados que se apresentam também os percentuais mais altos de inclusão digital, como São Paulo $(29,9 \%)$, Santa Catarina $(29,5 \%)$, Rio de Janeiro $(26,7 \%)$ e Paraná $(25,9 \%)$; enquanto isso, nos estados mais pobres e com zonas rurais mais depauperadas, como Alagoas e Maranhão, o percentual de pessoas consideradas como incluídas digitalmente não chega a $8 \%$ e pouco ultrapassa os $10 \%$ no Piauí, no Amazonas e no Pará.

Esse tipo de indicador de inclusão digital ${ }^{14}$ pode ser também avaliado em termos mundiais. A tabela 5 mostra as pronunciadas diferenças existentes no mundo. Nas partes mais desenvolvidas do

14 Ou seja, a mera avaliação do percentual de pessoas com acesso (qualquer acesso e qualquer grau de compreensão cognitiva) à internet. 
planeta, são elevados os percentuais de inclusão digital. Enquanto na Oceania/Austrália a inclusão digital é de cerca de $57 \%$ e na América do Norte atinge $71 \%$ (dados referentes apenas a EUA e Canadá), o índice é de apenas 4,7\% na África e 13,7\% na Ásia. Dados os elevados índices de inclusão digital na América do Norte e na Oceania, essas regiões concentram um percentual de internautas em relação ao total mundial muito superior às de suas respectivas populações (a América do Norte reúne $18 \%$ dos internautas do mundo, embora sua população represente apenas cerca de 5\% da população mundial; no outro extremo, pode-se citar o caso da Ásia, que, embora concentre cerca de $56 \%$ da população mundial, tem apenas cerca de 39\% dos internautas do mundo).

A tabela 6 ilustra a situação do Brasil dentro da América do Sul. 0 índice de inclusão digital do Brasil, segundo dados reunidos e divulgados pelo site da Internet World Stats, é de $22,4 \%$ e ocupa uma posição intermediária dentro do padrão da América do Sul. Argentina e Chile revelam relativamente altos índices de inclusão digital, enquanto em países como Suriname, Bolívia e Paraguai a inclusão digital não chega nem perto dos $10 \%$. Ou seja, mesmo dentro do continente sul-americano, existem expressivas diferenças nos indicadores de inclusão digital, dadas as significativas diferenças de grau de desenvolvimento econômico dentro dessa região.

TABELA 5 - Estatísticas de uso de Internet no mundo 2007

\begin{tabular}{|c|c|c|c|c|c|c|}
\hline $\begin{array}{l}\text { REGIÕES } \\
\text { DO MUNDO }\end{array}$ & $\begin{array}{c}\text { População } \\
\text { em } 2007 \\
\text { (estimativa) }\end{array}$ & $\begin{array}{l}\text { População } \\
\text { da região } \\
\text { em \% do } \\
\text { mundo }\end{array}$ & $\begin{array}{l}\text { Uso de internet } \\
\text { dados mais } \\
\text { recentes } \\
\text { (em núm. } \\
\text { absolutos) }\end{array}$ & $\begin{array}{c}\text { \% da } \\
\text { população } \\
\text { que acessa } \\
\text { internet } \\
\text { (penetração) }\end{array}$ & $\begin{array}{c}\text { uso da } \\
\text { internet } \\
\text { em \% do } \\
\text { uso mundial }\end{array}$ & $\begin{array}{c}\% \text { de } \\
\text { crescimento } \\
\text { do uso } \\
\text { entre } 2000 \text { e } \\
2007\end{array}$ \\
\hline ÁFRICA & 941.249 .130 & 14,2 & 44.361 .940 & 4,7 & 3,4 & 882,7 \\
\hline ÁSIA & 3.733 .783 .474 & 56,5 & 510.478 .743 & 13,7 & 38,7 & 346,6 \\
\hline EUROPA & 801.821 .187 & 12,1 & 348.125 .847 & 43,4 & 26,4 & 231,2 \\
\hline ORIENTE MÉDIO & 192.755 .045 & 2,9 & 33.510 .500 & 17,4 & 2,5 & 920,2 \\
\hline $\begin{array}{l}\text { AMÉRICA DO NORTE } \\
\text { AMÉRICA LATINA E }\end{array}$ & 334.659 .631 & 5,1 & 238.015 .529 & 71,1 & 18,0 & 120,2 \\
\hline CARIBE & 569.133 .474 & 8,6 & 126.203 .714 & 22,2 & 9,6 & 598,5 \\
\hline OCEANIA/AUSTRÁLIA & 33.569 .718 & 0,5 & 19.175 .836 & 57,1 & 1,5 & 151,6 \\
\hline TOTAL MUNDIAL & 6.606 .971 .659 & 100,0 & 1.319.872.109 & 20,0 & 100,0 & 265,6 \\
\hline
\end{tabular}

Fonte: Internet World Stats: usage and populations statistics.

Notas: dados referem-se a 31 de dezembro de 2007; população refere-se ao US Census Bureau; dados de uso da internet referem-se a dados publicados pela Nielsen/NetRatings, pela International Telecommunications Union, pela NIT local e por fontes confiáveis. México tem dados incluídos na América Central. 
TABELA 6 - Estatísticas de uso de Internet no mundo 2007

\begin{tabular}{|c|c|c|c|c|c|c|}
\hline $\begin{array}{l}\text { AMÉRICA } \\
\text { DO } \\
\text { SUL }\end{array}$ & $\begin{array}{l}\text { População } \\
\text { em } 2007 \\
\text { (estimativa) }\end{array}$ & $\begin{array}{c}\text { População } \\
\text { da região } \\
\text { em \% da Am. } \\
\text { Sul }\end{array}$ & $\begin{array}{l}\text { Uso de } \\
\text { internet } \\
\text { dados mais } \\
\text { recentes } \\
\text { (em núm. } \\
\text { absolutos) }\end{array}$ & $\begin{array}{c}\text { \% da } \\
\text { população } \\
\text { que acessa } \\
\text { internet } \\
\text { (penetração) }\end{array}$ & $\begin{array}{c}\text { uso da } \\
\text { internet } \\
\text { em \% do } \\
\text { uso da Am. do } \\
\text { Sul }\end{array}$ & $\begin{array}{c}\% \text { de } \\
\text { crescimento } \\
\text { do uso } \\
\text { entre } 2000 \text { e } \\
2007\end{array}$ \\
\hline ARGENTINA & 40.301 .927 & 10,6 & 16.000 .000 & 39,7 & 17,4 & 540,0 \\
\hline BOLÍVIA & 9.119 .152 & 2,4 & 580.000 & 6,4 & 0,6 & 383,3 \\
\hline BRASIL & 190.010 .647 & 50,0 & 42.600 .000 & 22,4 & 46,3 & 752,0 \\
\hline CHILE & 16.284 .741 & 4,3 & 7.035 .000 & 43,2 & 7,6 & 300,3 \\
\hline COLÔMBIA & 44.379 .598 & 11,7 & 10.097 .000 & 22,8 & 11,0 & 1050,0 \\
\hline EQUADOR & 13.755 .680 & 3,6 & 1.549 .000 & 11,3 & 1,7 & 760,0 \\
\hline ILHAS MALVINAS & 2.736 & 0,0 & 1.900 & 69,4 & 0 & n.d. \\
\hline GUIANA FRANCESA & 204.932 & 0,1 & 42.000 & 20,5 & 0 & 2000,0 \\
\hline GUIANA & 769.095 & 0,2 & 160.000 & 20,8 & 0,2 & 5233,3 \\
\hline PARAGUAI & 6.669 .086 & 1,8 & 260.000 & 3,9 & 0,3 & 1200,0 \\
\hline PERU & 28.674 .757 & 7,5 & 7.324 .300 & 25,5 & 8,0 & 193,0 \\
\hline SURINAME & 470.784 & 0,1 & 32.000 & 6,8 & 0,0 & 173,5 \\
\hline URUGUAI & 3.460 .607 & 0,9 & 1.100 .000 & 31,8 & 1,2 & 197,3 \\
\hline VENEZUELA & 26.023 .528 & 6,8 & 5.297 .798 & 20,4 & 5,8 & 457,7 \\
\hline TOTAL AM. DO SUL & 380.127 .528 & 100,0 & 92.078 .998 & 24,2 & 100,0 & 544,3 \\
\hline
\end{tabular}

Fonte: Internet World Stats: usage and populations statistics.

Notas: dados referem-se a 31 de dezembro de 2007; população refere-se ao US Census Bureau; dados de uso da internet referem-se a dados publicados pela Nielsen/NetRatings, pela International Telecommunications Union, pela NIT local e por fontes confiáveis.

Portanto, dado o quadro descrito nesta seção do artigo, parece claro que, no caso dos países mais pobres, existe um fator econômico limitante para a inclusão digital: a infra-estrutura que permite o acesso a linhas telefônicas e o aumento do número de computadores por habitantes (assim como a quantidade deles conectados à internet) mostra-se ainda bastante insuficiente. De qualquer forma, é importante mencionar que o caso brasileiro, o que mais interessa neste artigo, é bastante peculiar pelo fato de ter se caracterizado por um crescimento espetacular da rede (WILSON, 2000; SILVEIRA E CASSINO (org.), 2003), quer o fenômeno seja avaliado pelo crescimento do número de hosts, quer pelo número absoluto de pessoas "digitalmente incluídas" a cada ano.

Bolaño (2003) está entre os autores que destaca que a expansão recente da internet no Brasil foi expressiva, especialmente a partir da segunda metade da década de 1990, colocando o país entre os 11 primeiros colocados no mundo em número de hosts ${ }^{15}$ (em 1996, o país estava na décima-nona posição). Tal ascensão revela, sem dúvida, que a expansão recente da Internet no Brasil foi significativa, comparado ao desempenho mundial deste indicador. É claro que, num país eivado de

15 Outro indicador da expansão da Internet no Brasil é dado pela evolução do número de domínios no Brasil. Entre 1996 e 2000, o número de domínios cresceu de 7.574 para 174.163, segundo o Livro Verde da Sociedade da Informação no Brasil (TAKAHASHI, 2000). 
desigualdades como o Brasil, uma grande parte dos acessos registrados pode estar se referindo a situações de dupla contagem, ou seja, revelando o caso de pessoas que tenham acesso tanto em casa quanto no trabalho, quando não também em uma terceira situação.

De qualquer forma, pode-se considerar não apenas que o crescimento do acesso à internet foi expressivo nos últimos anos (o que explica essa expansão do número de hosts no mercado brasileiro), mas também que o número absoluto de pessoas conectadas à internet é significativo, dado que a população brasileira é uma das maiores do mundo. Há que se considerar, porém, que, provavelmente, o ritmo de expansão da "inclusão digital" (qualquer que seja a forma de medição do fenômeno), daqui em diante, se arrefeça bastante, pois é quase certo que a grande maioria das pessoas pertencentes aos extratos mais elevados de renda do país que queiram e precisem se conectar à internet já estejam de fato conectadas.

Portanto, dado que a expansão do acesso à internet no Brasil pode ter chegado já a todas ou quase todas as pessoas que têm certo patamar de rendimentos e que queiram se inserir digitalmente (ou seja, que tenham recursos financeiros e desejo para adquirir um computador e uma linha telefônica e pagar para usar um provedor de acesso), fica o desafio para que, nos próximos anos, mantenha-se o atual ritmo de ampliação da inclusão digital no país. A elevada concentração de renda e o baixo nível do rendimento médio da população brasileira representam, portanto, um significativo entrave para a manutenção de uma contínua ampliação do grau de inclusão digital no Brasil no futuro breve.

Dessa maneira, torna-se cada vez mais imperiosa a necessidade de se constituírem políticas públicas de acesso da população brasileira aos mais modernos recursos das Tecnologias de Informação e Comunicação (TIC's), dentre as quais a internet talvez seja o maior símbolo. De todo modo, não se pode negar a existência de diversos casos exitosos de políticas públicas de inclusão digital no país, conforme demonstram, aliás, relatos reunidos e analisados em livros organizados por SILVEIRA e CASSINO (2003), bem como por AUN et alli (2007) e também por JAMBEIRO et alli (2007) e ainda por MACIEL e ALBAGLI (2007), entre outros $^{16}$. Em outras palavras: parece que já atingiu o seu estertor a inclusão digital que poderia ser obtida pelo simples fato de as TIC's estarem disponíveis no país e pelo também simples fato de existir uma parcela da população que pode arcar com as despesas relacionadas ao consumo e ao uso dessas tecnologias. Em outras palavras, a inclusão digital decorrente da "livre" atuação das chamadas "forças de mercado" parece ter se esgotado. De agora em diante, para que independentemente dos critérios metodológicos utilizados para avaliar os indicadores de inclusão digital no país - a taxa de crescimento da inclusão digital brasileira tenha o mesmo ritmo de crescimento que apresentou entre 1995 e 2005, são necessárias políticas públicas que evitem a exclusão pela renda do acesso às TIC's, pois essas tecnologias exigem

16 Cf. referências bibliográficas. 
gastos maiores do que por exemplo o que se gasta para ter um rádio ou uma TV em uso cotidiano (para mencionar dois exemplos óbvios de outros meios de informação e comunicação já existentes e já amplamente massificados).

\section{Limites e condicionantes das políticas públicas de inclusão digital}

As políticas públicas visando a uma melhoria dos indicadores de inclusão digital devem ser concebidas e analisadas no contexto dos dados apresentados e comentados acima, que revelam as perspectivas do cenário social brasileiro e aspectos acerca da exclusão digital no país e também que demonstram que a expansão do uso e do domínio das TIC's não foram suficientes para reduzir o fosso existente entre países ricos e países pobres e nem mesmo entre pobres e ricos dentro dos países, conforme têm demonstrado diversos estudos, alguns dos quais relatados nas duas partes iniciais deste artigo.

Os dados referentes ao Brasil, em especial, demonstram que a expansão da oferta de TIC's e do número de acessos à internet, deixados pelos movimentos "naturais" das "forças de mercado" (LOPES, 2007) e portanto à mercê das estratégias das grandes empresas pertencentes aos monopólios informacionais, não serão suficientes para de fato promover uma significativa redução do fosso digital existente no país; ademais, não serão suficientes para promover uma melhoria da desigualdade social a partir de um eventual êxito no processo de expansão do número de "infoincluídos" e de uma eventual melhoria dos indicadores de desigualdade de acesso às TIC's. Deve-se destacar que é no meio digital, conforme lembram Aun e Angelo (2007), que se encontram os maiores estoques de informações, e, portanto, o acesso ao meio digital (ou seja, a efetiva inclusão digital) é fundamental para que não surjam novos elementos de ampliação das diferenças entre os cidadãos. O risco do fracasso da implementação dessas políticas públicas de inclusão digital é que sejam geradas "uma nova divisão social entre os que têm o monopólio do pensamento, da transformação da informação em conhecimento e os que estão excluídos desse processo" (Aun e Ângelo, 2007, p. 66).

Silveira (2005) está entre os que apregoam a importância de se implementar políticas públicas como forma de reduzir a "infoexclusão". O autor assevera que "a luta pela inclusão digital pode ser uma luta pela globalização contra-hegemônica se dela resultar a apropriação pelas comunidades e pelos grupos sociais socialmente excluídos da tecnologia da informação". No mesmo estudo, o autor destaca a existência, atualmente, de uma enorme assimetria em termos de acesso às TIC's em âmbito mundial e lembra que, na verdade, historicamente, sempre o acesso às tecnologias representou instrumento de poder e fonte de apropriação da riqueza social produzida.

É nesse sentido que o referido autor destaca que há um conjunto de fatores que justificam a elaboração e implementação de políticas públicas 
de inclusão digital. Em primeiro lugar, por causa do reconhecimento de que a exclusão digital amplia a miséria e coloca obstáculos ao desenvolvimento econômico em geral e ao desenvolvimento das habilidades pessoais, em particular. O autor também lembra que a própria alfabetização tradicional não teria se tornado possível se a educação não tivesse se tornado, historicamente, na maioria dos países, política pública e gratuita. Outra questão abordada pelo autor deve ser analisada de perto: a velocidade do processo de inclusão digital também é muito importante. Também Sorj e Guedes (2005, p. 102) abordam essa questão, na seguinte passagem:

(...) como o ciclo de acesso a novos produtos começa com os ricos e se estende aos pobres após um período de tempo mais ou menos longo (e que nem sempre se completa), há aumento da desigualdade. Os ricos são os primeiros a usufruir as vantagens do uso e/ou domínio dos novos produtos no mercado de trabalho, enquanto a falta destes aumenta as desvantagens dos grupos excluídos. Em ambos os casos, os novos produtos TIC's aumentam, em princípio, a pobreza e a exclusão digital.

Os autores mencionados destacam, portanto, que a demora com que as novas tecnologias são absorvidas pelos mais pobres (sempre há uma defasagem de tempo entre o momento em que as novas tecnologias são absorvidas pelos mais ricos e pelos mais pobres, notadamente quando a diferença de renda e de riqueza entre eles é muito elevada, como é o caso do Brasil) é fator decisivo para a perpetuação e até eventual aumento das desigualdades, especialmente se considerarmos que os que absorvem primeiro as novas tecnologias desfrutam de vantagens, de certo "poder de monopólio"17 temporário (mais ou menos duradouro, dependendo da dimensão da defasagem de tempo), que se materializa em melhores oportunidades no mercado de trabalho e em melhores condições de acesso a bens, serviços e informações proporcionados pela inclusão digital.

É por isso que a necessidade de políticas públicas de inclusão digital se impõe, pois a introdução inicial das TIC's, na verdade, aprofunda as desigualdades existentes e mesmo cria novas assimetrias sob o Capitalismo Contemporâneo.

A restrição econômica para o aumento da oferta de TIC's também representa elemento importante a ser considerado quando se discutem políticas de inclusão digital. Essa restrição se manifesta não apenas no óbvio problema da necessidade de recursos por parte do Estado para

17 Conforme conceito presente na obra do eminente economista Joseph Schumpeter. No capítulo 8 de sua obra "Capitalismo, Socialismo e Democracia", Schumpeter explica que a inovação permite ao empresário inovador desfrutar de certo "poder de monopólio" que the confere lucros extraordinários enquanto os demais concorrentes não conseguem imitar a inovação. Analogamente, o acesso aos conhecimentos propiciados pelas novas tecnologias de informação e comunicação permite àqueles que inicialmente têm acesso a elas desfrutar de vantagens profissionais, econômicas e culturais enquanto outras pessoas (normalmente já originalmente mais pobres) não conseguem também lograr a oportunidade de também se incluírem "digitalmente". 
dotar a sociedade de quantidades crescentes de equipamentos, inclusive enfrentando as dificuldades inerentes à própria rapidez da proliferação dos ganhos tecnológicos, os quais exigem constantes aportes de capital para manter-se atualizados ${ }^{18}$. Daí a necessidade de se obter um ambiente macroeconômico em expansão, que viabilize a ampliação da arrecadação de impostos e ampliação do orçamento da União, dos estados e municípios; ademais, as políticas de treinamento e capacitação dos profissionais que vão operar e ensinar a operacionalização os equipamentos para crescentes parcelas da população exige também crescentes gastos por parte do poder público.

A população que deseja ter acesso às TIC's e dominar seu conteúdo de uma maneira pelo menos razoável enfrenta também as restrições impostas pela exclusão pela renda. É por isso também que se torna imperiosa a adoção de abrangentes e substanciais políticas públicas de inclusão digital, notadamente no Brasil, país marcado por acentuada concentração pessoal da renda e por notória heterogeneidade regional. Discutindo as peculiaridades de um país pobre e desigual, Barros et alli (2007) argumentam que:

(...) a inclusão digital é um elemento importante nas políticas para a Sociedade da Informação, especialmente naqueles países que apresentam um maior grau de desigualdade social, que advém de processos históricos de sua formação. Nesses casos, o desafio é duplo: superar antigas deficiências e criar competências requeridas pelas novas necessidades culturais e socioeconômicas da sociedade. (BARROS et alli, 2007; p. 201)

Kroner e Weinstein (1994) também argumentam que as TIC's não representam uma tecnologia democratizadora e inclusiva pela sua própria existência, mas, pelo contrário, acabam acentuando as desigualdades e assimetrias existentes nas sociedades contemporâneas à medida que se expandem. Essa avaliação vale também - e de forma até mais enfática para o Brasil, dadas a enorme desigualdade de renda do país e dada também a conhecida deficiência da Educação Básica brasileira (fica aqui a pergunta: como construir uma sociedade de "infoincluídos" em uma sociedade marcada por relativamente altas taxas de analfabetismo funcional?). Nesse sentido, é fundamental que a inclusão digital seja definitivamente inserida no processo educacional brasileiro, constituindose como parte dos valores sociais que permitam aos indivíduos exercerem sua plena cidadania dentro do ambiente escolar e já desde tenra idade.

18 Deve-se destacar que a inclusão digital pode também ser avaliada pela qualidade do acesso. Ou seja, é muito impreciso considerar igualmente como um "incluído" digital tanto alguém que tenha acesso à internet pela linha discada quanto alguém que o tenha por uma tecnologia de banda larga. As formas de medição mais difundidas dos indicadores de inclusão digital a definem simplesmente pela relação percentual entre as pessoas com acesso à internet (independentemente da qualidade do acesso) e o total da população. Mas essa forma de medição - um tanto simplória - esconde na verdade algumas diferenças de qualidade do acesso. Isso deveria também ser levado em conta nos estudos de indicadores de inclusão digital e também exige constantes aportes de capital por parte do poder público na elaboração e manutenção de políticas públicas de inclusão digital. O desafio, portanto, parece ser maior ainda do que normalmente indica a literatura, notadamente se esta literatura se orienta pelos indicadores mais prosaicos de inclusão digital. 
De qualquer forma, é preciso destacar que há inúmeros projetos de inclusão digital promovidos por ONG's, de diversos matizes e em diversas regiões do Brasil. Há também inúmeras iniciativas de prefeituras de cidade de todos os tamanhos, além dos projetos do governo federal. Não seria viável enumerá-los aqui e seria pouco conclusivo tomar alguns, isoladamente, para análise. Tal tarefa, portanto, não está nos objetivos deste artigo. O que se pretende afirmar, de todo modo, é que, a despeito da relevância de boa parte desses projetos do Terceiro Setor, a somatória dessas iniciativas jamais terá o alcance dos projetos conduzidos pelo setor público $^{19}$, especialmente se estes representarem iniciativas do governo federal consolidadas como políticas permanentes de Estado. Ademais, deve-se insistir na necessidade de que essas políticas públicas de inclusão digital sejam acopladas a programas também abrangentes de incremento na qualidade das políticas educacionais, de tal forma que a questão cognitiva possa ser mais bem apreendida no contexto da ampliação das políticas públicas de inclusão digital, que não podem, obviamente, limitarse ao mero aumento da oferta de equipamentos de TIC's, o que apenas favoreceria o "mercado" de negócios das empresas envolvidas na produção desses equipamentos, conforme alerta Silveira (2007). A apreensão dos conteúdos gerados pelas TIC's promove não apenas a óbvia ampliação e democratização do conhecimento, como também uma mais equânime apropriação da riqueza social produzida pela "Sociedade da Informação e da Comunicação", ao permitir inserção mais qualificada dos mais pobres no mercado de trabalho, sem contar as melhores condições de acesso à cultura e ao entretenimento por parte de camadas cada vez mais amplas da população.

Em suma, o que se apregoa neste artigo é que, para avaliar os efeitos das políticas de inclusão digital sobre a vida dos indivíduos seria importante definir um conjunto de indicadores que compare a vida das pessoas antes e depois de terem participado de programas de inclusão digital. Fundamentalmente, deve-se avaliar se de fato ocorreu inclusão social e melhoria das condições de vida dos indivíduos que, segundo a metodologia utilizada pelo IBGE, passaram a ser computados como pessoas "digitalmente incluídas".

Os indicadores a serem definidos deveriam medir, por exemplo, se houve melhor inserção do indivíduo no mercado de trabalho e se essa inserção deveu-se às habilidades eventualmente aprendidas em algum programa específico de inclusão digital que está a ser avaliado (pode ocorrer, por exemplo, uma melhor inserção do indivíduo no mercado de trabalho simplesmente por que a economia teria voltado a crescer e, nesse caso, a melhoria das condições profissionais da pessoa não estaria associada a um eventual êxito do programa de inclusão digital por ela freqüentado). Outro fator importante é avaliar não apenas se a pessoa está habilitada para a "navegabilidade" na rede mundial de computadores,

19 Nesse mesmo sentido, Martini (2005, P. 1) afirma que a alfabetização da população "não seria massiva se não fosse pela transformação da educação em política pública". 
mas se ela adquiriu habilidades e conhecimento para utilizar pelo menos um editor de texto e algum tipo de planilha de cálculo, por exemplo.

A regularidade de acesso por parte dos "incluídos digitais" também representa algo que deveria ser medida e avaliada, algo que, conforme argumentado neste artigo, revela-se bastante deficiente nos indicadores do IBGE, pois o mesmo considera como incluído digital o indivíduo que tenha tido pelo menos um acesso à internet nos últimos 3 meses. Uma definição mais abrangente e coerente de indicadores de inclusão digital deveria, portanto, incluir também critérios para quantificar a habitualidade de acesso.

A leitura de trabalhos recentes sobre políticas públicas de inclusão digital sugere que as mesmas deveriam se nortear por 5 aspectos fundamentais:
a) Inserção no mercado de trabalho e geração de renda;
b) Melhorar relacionamento entre cidadãos e poderem públicos $^{20}$;
c) Melhorar e facilitar tarefas cotidianas das pessoas, o que pode incluir aspectos do item anterior;
d) Incrementar valores culturais e sociais e aprimorar a cidadania;
e) Difundir conhecimento tecnológico.

Os vários objetivos destacados pelas políticas de inclusão digital em diversos artigos reunidos na literatura mais recente sobre o tema ${ }^{21}$ estão inseridos em pelo menos um dos aspectos acima mencionados. A classificação sugerida acima, em cinco itens, engloba os principais aspectos envolvidos nos objetivos das políticas públicas de inclusão digital. A literatura sobre esse tema muitas vezes se debruça na análise de programas específicos. Seria interessante que a ampla gama de instituições devotadas a desenvolver programas e políticas de inclusão digital se reunissem, sob a coordenação de alguns Ministérios (Ciência e Tecnologia e Educação certamente incluídos, pelo menos), para elaborar indicadores de avaliação dos programas de inclusão digital, que possam avaliar cada uma dessas políticas ao longo do tempo, e também para que possam permitir uma comparação entre elas.

Para que o Brasil possa finalmente definir uma política nacional de inclusão digital que "articule as esferas federal, estaduais e municipais,

20 Aqui estão incluídas situações de marcação de consultas médias ou internações hospitalares, consulta à programação cultural e de lazer da cidade em que vive, pagamentos de certas contas, pagamento de Imposto de Renda etc. Todas essas tarefas colaboram para o aumento do tempo disponível para as pessoas poderem usufruir melhor de atividades de lazer, de entretenimento e também para descanso. Cabe lembrar que, notadamente nas camadas mais desfavorecidas da população, o tempo despendido nessas atividades pelos meios convencionais, especialmente nas grandes metrópoles, é enorme, não apenas pelas dificuldades do setor de transportes, mas também pela própria morosidade do serviço público, normalmente por causa da pequena quantidade de funcionários públicos destinados para essas funções.

21 Cf. especialmente os diversos artigos reunidos em AUN et alli (2007), JAMBEIRO et alli (2007), SILVEIRA e CASSINO (2003) e MACIEL e ALBAGLI (2007). Muitos dos artigos reunidos nesses livros tratam de políticas específicas de inclusão digital e relatam objetivos que podem, de alguma maneira, ser classificados em pelo menos um dos fatores acima definidos. 
sociedade civil e as instituições voltadas à pesquisa e educação" (ALBUQUERQUE, 2007) é necessário definir indicadores que avaliem a evolução dos 5 fatores mencionados acima e é preciso determinar critérios para aferi-los junto às pessoas que tiverem freqüentado programas de inclusão digital. Tais indicadores devem ser passíveis da construção de séries históricas que permitam compará-los ao longo do tempo. O desafio é enorme na definição desses indicadores, pois há evidentes aspectos subjetivos envolvidos (por exemplo: o que significa acessar sítios de internet com conteúdo voltado a cultura/entretenimento?). Além disso, deve-se salientar que as necessidades das pessoas variam muito dependendo de fatores regionais e culturais, assim como os padrões de consumo variam muito historicamente. Dessa maneira, os indicadores escolhidos teriam de ter certa flexibilidade para serem adaptados periodicamente, segundo critérios conhecidos e bem definidos, mas essa flexibilidade não pode deteriorar a capacidade dos indicadores de serem passíveis de se prestar à construção de séries históricas, conforme mencionado ${ }^{22}$. Por fim, mas não menos importante, a avaliação da capacidade cognitiva do usuário de internet pode ser avaliada pela sua competência para gerar conteúdos na rede, e não apenas acessar os conteúdos já existentes.

As sugestões de melhoras de indicadores, portanto, são muitas e são controversas. A única certeza que se vislumbra é a de que esses indicadores precisam ser definidos em âmbito ministerial e devem servir tanto para avaliar políticas de inclusão digital elaboradas por entidades públicas, quanto por entidades privadas, incluindo ONG's. As políticas públicas devem ter a característica da objetividade e da continuidade também. Precisam ser céleres a ponto de se adaptarem às contínuas mudanças tecnológicas que caracterizam as sociedades contemporâneas, bem como também as mudanças na vida social e cultural. Além disso, fundamentalmente, as políticas devem assumir o caráter de políticas de Estado, e não iniciativas isoladas de governos específicos ou de ONG's que podem, em qualquer momento, deixar de existir.

22 Uma comparação pode ser feita com relação aos indicadores de evolução dos preços na economia brasileira. Várias instituições pesquisam preços e divulgam índices de inflação a cada mês (ou a cada semana, em alguns casos) e esses índices mensais podem ser comparados em longas séries históricas. Cada instituição tem um critério pré-definido e uma metodologia de cálculo (por exemplo: período de coleta de dados; índice estatístico específico escolhido para calcular a dispersão de preços; locais de coleta de preços; ponderação estatística dos preços de cada um dos produtos e serviços específicos cujos preços são incluídos na amostra; cidades e/ou regiões em que os preços são coletados etc.). Com o passar do tempo, porém, as instituições fazem pequenas modificações em alguns aspectos da coleta de dados, uma vez que mudanças na vida social e econômica vão ocorrendo ao longo dos anos. Por exemplo: nos anos mais recentes, a "alimentação fora da residência" tornou-se um hábito cada vez mais freqüente, especialmente nas grandes cidades, razão pela qual o preço dessas refeições têm tido peso crescente na composição dos diferentes Índices de Preços. Nos últimos tempos, também tem aumentado a proporção dos gastos com Educação no orçamento das famílias, então a ponderação desse item do índice (Educação) tem aumentado nas planilhas de cálculo dos índices. Há também serviços e produtos novos que surgem, e que passam a fazer parte do padrão de consumo das pessoas, como telefone celular, por exemplo, e que, portanto, passam a ser incluídos nos índices. Os indicadores precisam se adaptar a essas mudanças da vida social e econômica, mas as alterações nas metodologias de cálculo dos índices precisam ter critérios pré-definidos e consistentes, de forma que não se perca a validade da série histórica de cada um desses indicadores. 


\section{Conclusões}

As novas TIC's têm redefinido as formas de sociabilidade entre as pessoas e têm determinado alterações importantes nos padrões de consumo e nas possibilidades de acumulação de capital sob a atual ordem econômico-financeira internacional. Esse novo padrão tecnológico também alterou profundamente a natureza da concorrência intercapitalista, redefinindo as estratégias de atuação das grandes empresas.

Tanto o papel desempenhado pela inclusão digital, quanto as possibilidades de o acesso às novas tecnologias se expandir, precisam ser avaliados de forma mais crítica. Em primeiro lugar, deve-se lembrar que, notadamente em um país como o Brasil, muitas vezes o fato da pessoa estar "digitalmente incluída" pressupõe que ela fosse previamente já também socialmente incluída. Está para ser mais bem analisada também a real dimensão que a inclusão digital pode ter na ascensão social e na melhoria efetiva do acesso das pessoas digitalmente incluídas (segundo os critérios mais tradicionais usados para medir esse indicador) às informações e na efetiva democratização das mesmas. Ou seja, ainda está por ser mais bem avaliada, pela maior parte da literatura especializada, a verdadeira democratização das oportunidades de acesso e compreensão das informações disponibilizadas em rede.

O surgimento da imprensa escrita, e depois também o surgimento do rádio e da televisão, apesar de todas as previsões otimistas de cada uma dessas épocas e a despeito do fascínio que essas tecnologias provocaram - em cada época - nas pessoas em geral e nos intelectuais, em particular, não foram capazes de promover por si sós a efetiva democratização das informações e nem de fomentar uma maior homogeneidade social.

$O$ que os estudos mais recentes e relevantes sobre exclusão/inclusão digital mostram é que o grau de desenvolvimento econômico define os limites da dimensão da inclusão digital de uma sociedade. A própria medida de inclusão já é por si só problemática e mereceria uma análise mais complexa (e que incluísse, pelo menos, algum grau de avaliação qualitativa dessa inclusão - o que não é tão simples - e que se relacionasse a alguma forma de avaliação da capacidade cognitiva por parte da população "conectada").

Pode-se afirmar que a renda per capita e o custo de acesso são fatores limitantes para a inclusão digital. Nos países pobres, é percentualmente pequeno o número de pessoas que desfrutam de recursos para ter uma linha telefônica, um computador e ainda podem pagar um provedor de acesso (ou então ter, pelo menos, uma inserção profissional ou acadêmica que lhe permita acessar a Internet fora de seu domicílio de maneira regular e diária, se necessário). O desafio para a massificação da inclusão digital nesses países é particularmente difícil, pois existe a necessidade também de se dotar suas respectivas populações de uma melhor capacidade cognitiva para acessar e processar as informações. Tal fato parece óbvio, mas não existem ainda trabalhos que consigam, nem minimamente, "medir" essa capacidade cognitiva - o 
que compromete a qualidade dos indicadores mais tradicionais $^{23}$ de "inclusão digital".

A formulação de políticas públicas, no Brasil, deve abarcar não apenas uma decisão de investimento em bens materiais (compra de equipamentos, ampliação de linhas telefônicas etc.), mas também uma contínua melhoria das condições do ensino básico, que possa dotar a população em idade escolar de capacidade cognitiva para compreender e processar as informações e símbolos disponibilizados pelo acesso dessas pessoas à Internet. Ou seja, para que também as camadas de baixa renda possam ter cada vez maior capacidade de exploração, de interpretação e de uso do enorme mundo de informações disponibilizado pela Internet.

Até agora, no Brasil, a maior parte do processo de inclusão digital deu-se "pelo mercado", ou seja, apenas referendou a inclusão de pessoas em condições financeiras e cognitivas de acessar a internet e dominar seus requisitos básicos. À medida que o acesso às TIC's virou negócio e deixou de estar restrito às universidades e centros de excelência em pesquisa científica (conforme ocorria, por exemplo, nos EUA, nos anos 1950 e 1960; por outro lado, a partir dos anos 1980, nos EUA, e a partir de meados dos anos 1990, no Brasil, o acesso à internet massificou-se), aumentou expressivamente o número absoluto de pessoas classificadas como "digitalmente incluídas". Deve-se salientar que, assim como foi necessário que a educação se tornasse política pública no país para que o analfabetismo fosse reduzido substancialmente, também no caso da inclusão digital (ou da superação do chamado "analfabetismo digital") será necessária a elaboração de políticas públicas e que o Estado tome as rédeas desse processo de ampliação da inclusão digital, assumindo seu papel na promoção de todas as camadas da população em direção ao domínio das TIC's.

O desafio, além de complexo, é urgente no tempo, pois quanto mais ele demora, maiores serão as desvantagens relativas das parcelas apartadas do efetivo acesso às TIC's, consolidando e até mesmo ampliando a exclusão social e a desigualdade de oportunidades já existentes no Brasil.

Deve-se destacar que a atual revolução tecnológica, ao contrário da primeira e da segunda Revoluções Industriais, baseia-se nas chamadas tecnologias da inteligência e, portanto, requer maiores esforços cognitivos por parte das pessoas para transformar informações em conhecimento, obtendo, assim, capacidade de inserção mais qualificada no mercado de trabalho, especialmente à medida que um crescente conteúdo da vida profissional, cultural e mesmo material vai migrando para a rede e nela se amplificando e atingindo todas as esferas da vida social. Nesse sentido, Barros et alli (2007) evocam importantes argumentos destacando que "políticas de inclusão devem estar relacionadas à organização social e à

23 Como, por exemplo, o número de pessoas conectadas à Internet ou o número de PC's conectados à Internet. Estes indicadores são os mais comumente utilizados para medir o grau de inclusão digital de diferentes sociedades. Não resta dúvida de que são indicadores importantes e que podem ser comparáveis entre diversos países, mas o fenômeno da inclusão digital é algo mais complexo, que não se resume apenas a algo que possa ser avaliado quantitativamente, conforme argumentos apresentados em diversas passagens deste texto. 
cultura política dos povos"24. Dessa forma, Barros et alli (2007) revelam preocupação de que programas de inclusão não podem estar apartados de outros esforços empreendidos pelo poder público no sentido de qualificar a vida social dos cidadãos, o que inclui eventos relacionados à geração de emprego, moradia, educação, participação política e social, entre outros fatores. Ou seja, a mera oferta de novos equipamentos de TIC não é condição suficiente para que se processe de fato um mecanismo eficiente de inclusão digital e social.

Existe certa literatura ufanista a respeito do papel das TIC's nas sociedades contemporâneas. A contribuição deste artigo se contrapõe a essas interpretações laudatórias, bastante encontradiças na literatura que trata das novas tecnologias de informação e comunicação. Essa mesma literatura acerca das novas TIC's promove a idéia de que a mera existência dessas tecnologias, por si só, permite a melhoria das condições econômicas e sociais de uma parcela supostamente cada vez maior da população dos diferentes países. Entretanto, o que ocorre é exatamente o contrário. Deixadas às "forças do mercado", as novas tecnologias tendem a promover uma acentuação das desigualdades. Uma eventual ampliação dos investimentos produtivos em geral e a adoção de políticas distributivas de renda é que gerarão melhores possibilidades de ampliação do acesso e da oferta de equipamentos de TIC's. A exclusão ao acesso às TIC's pela renda diminui quando a renda média da sociedade cresce. Isso parece óbvio, mas é importante que seja destacado que a ordem de determinação parece ser da renda para a melhoria das condições de acesso às novas tecnologias e não o contrário.

Sendo assim, é importante destacar que a adoção de políticas públicas consistentes, duradouras e amplas de inclusão digital torna-se mais viável apenas se o contexto macroeconômico do país for marcado por uma combinação de crescimento da renda média da população (se esta ampliação da renda for acompanhada de uma melhoria de seu perfil distributivo, tanto melhor) e de ampliação da taxa de investimentos públicos e privados. É em um contexto como esse que o Estado teria melhores condições materiais para destinar recursos para políticas públicas de inclusão digital e a população em geral ver-se-ia em melhores condições também para absorver os conhecimentos e aproveitar as possibilidades geradas pelo uso mais habitual e intensivo dos equipamentos de tic's.

\section{Referências}

ALBUQUERQUE, H.H.F.S. A apropriação e o uso das tecnologias de informação para a atuação cidadã. In: AUN, M.P. (org.) MOURA, M.A ., SILVA, H.P., JAMBEIRO, O. (pesquisadores); ÂNGELO, E. S., ALBUQUERQUE, H.F.S., CÂMARA, M.A . (alunos pesquisadores). Observatório da inclusão digital: descrição e avaliação dos indicadores

24 Barros et alli (2007), p. 197. 
adotados nos programas governamentais de infoinclusão. Belo Horizonte: Gráfica Orion, 2007.

AUN, M.P. (org.) MOURA, M.A ., SILVA, H.P., JAMBEIRO, $O$. (pesquisadores); ÂNGELO, E. S., ALBUQUERQUE, H.F.S., CÂMARA, M.A. (alunos pesquisadores). Observatório da inclusão digital: descrição e avaliação dos indicadores adotados nos programas governamentais de infoinclusão. Belo Horizonte: Gráfica Orion, 2007.

AUN, M. P. e ÂNGELO, E.S. Observatório da Inclusão Digital. In: AUN, M.P. (org.) MOURA, M.A ., SILVA, H.P., JAMBEIRO, O. (pesquisadores); ÂNGElO, E. S., ALBUQUERQUE, H.F.S., CÂMARA, M.A . (alunos pesquisadores). Observatório da inclusão digital: descrição e avaliação dos indicadores adotados nos programas governamentais de infoinclusão. Belo Horizonte: Gráfica Orion, 2007.

BARROS, S., ANDRADE, R.S., FERREIRA, F., NASCIMENTO, L., FERREIRA, F., SIMÕES, C., SILVA, H.P. e JAMBEOR, O. Digitalizando a Inclusão Social: o caso do Liceu de Artes e Ofícios da Bahia. In: JAMBEIRO, O., SILVA, H.P. e BORGES, J. (Org.). Cidades Contemporâneas e Políticas de Informação e Comunicações. Salvador (BA); Ed. UFBA, 2007.

BOLAÑO, C.R.S. Economia Política da Internet. Universidade Federal de Sergipe (UFS), 2003.

CASTELLS, M.. A Sociedade em Rede. A era da informação: economia, sociedade e cultura, vol. 1. São Paulo: Paz e Terra, 1999.

DIEESE. Anuário dos Trabalhadores. São Paulo: DIEESE, $2001 a$.

DIEESE. A Situação do Trabalho no Brasil. São Paulo: DIEESE, 2001b.

FARAH, P.D. Nem 5\% do mundo usa Internet, diz ONU. Folha de S.Paulo, edição de 23 de junho de 2001.

FERREIRA, F., SPENCE, J., JAMBEIRO, O. Comparando iniciativas governamentais e não-governamentais de inclusão digital nos Estados Unidos e no Brasil. In: JAMBEIRO, O., SILVA, H.P. e BORGES, J. (Org.). Cidades Contemporâneas e Políticas de Informação e Comunicações. Salvador (BA); Ed. UFBA, 2007.

FGV. Mapa da Exclusão Digital. Rio de Janeiro: FGV, 2001.

GARNHAM, N. La Sociedad de la Información como ideología: uma crítica. IN: PRIMER FORO DE LAS COMUNICAICONES: DESAFIOS DE SOCIEDAD DE LA INFORMACIÓN EN AMÉRICA LATINA Y EM EUROPA, 2000. UNICOM/Lom Ed. Santiago (Chile), 2000.

IBGE. Contas Regionais do Brasil. Rio de Janeiro: IBGE, 2004.

IBGE, Diretoria de Pesquisas. Pesquisa Nacional por Amostra de Domicílios (PNAD), 2005.

IMF. World Economic Outlook, 2007.

INTERNET WORLD STATS. Usage and Population Statistics. 2008. 
JAMBEIRO, O., SILVA, H.P. e BORGES, J. (Org.). Cidades Contemporâneas e Políticas de Informação e Comunicações. Salvador (BA); Ed. UFBA, 2007.

KRONER, A. e WEINSTEIN, M. Data trash: the theory of the virtual class. [S.1]: St. Martin, 1994.

LASTRES, H. M. M. et ALBAGLI, S. (org.) Informação e Globalização na Era do Conhecimento. Rio de Janeiro: Ed. Campus, 1999.

LOPES, C.A. Exclusão Digital e a Política de Inclusão Digital no Brasil - o que temos feito? EPTIC ON LINE. Vol. IX, n.2, may-ao-2007.

MACIEL, M.L e ALBAGLI, S. (org.). Informação e Desenvolvimento: conhecimento, inovação e apropriação social. Brasil: IBICT, UNESCO, 2007.

MARQUES, I.C. O Brasil e a abertura dos mercados: o trabalho em questão. Rio de Janeiro: Contraponto, 2002.

MARTINI, R. Inclusão digital \& inclusão social. IBICT. Publicado em convênio com o Ministério da Ciência e Tecnologia. Acesso em 23/04/2007, no endereço: WWW.ibict.br/revistainclusaosocial/viewarticle. php $\mathrm{id}=7 \&$ layout $=\mathrm{html}$

MATTOS, F. A. M. Emprego e Distribuição de Renda nas Regiões Metropolitanas de São Paulo e do Rio de Janeiro: os anos 80. Dissertação (Mestrado em Economia) - Instituto de Economia. Campinas:UNICAMP, 1994.

A Importância do Estudo da Evolução da Distribuição da Renda do Trabalho. Cadernos da FCECA (6), publicação semestral da Faculdade de Ciências Econômicas, Contábeis e Administrativas da PUC de Campinas, vol. 4, no. 1, p. 76-87, jan./jun.1995.

- Distribuição regional da renda no Brasil: determinantes históricos e perspectivas. Cadernos da FACECA (8), publicação semestral da Faculdade de Ciências Econômicas, Contábeis e Administrativas da PUC de Campinas, vol. 5, no.1, p. 23-55, jan./jul.1996.

Transformações nos mercados de trabalho dos países capitalistas desenvolvidos a partir da retomada da hegemonia americana. Tese (Doutorado em Economia) - Instituto de Economia. Campinas:UNICAMP, 2001.

- Exclusão digital e exclusão social: elementos para uma discussão. Transinformação, Campinas (SP), v. 15, n. 03, p. 91-115, outdez, 2003.

OCDE. Economic Outlook. Paris: OCDE, 2001.

PETERS, T. Combate à Exclusão Digital. Questões Globais. Nov. 2003.

PETRELLA, R. Vers um techno-apartheid. Maniere de Voir. 18, p. 31, mai. 1993. 
POCHMANN, M. O Trabalho sob Fogo Cruzado. São Paulo: Ed. Contexto, 1999.

2001. . O emprego na Globalização. São Paulo: Boitempo Editorial,

PROENZA, F. e-Para Todos. IN: SILVEIRA, S e CASINO, J. (Org.). Software Livre e Inclusão Digital. São Paulo: Conrad Editora do Brasil, 2003.

RAMONET, I. Geopolítica do Caos. Petrópolis (RJ): Ed. Vozes, 1998.

SCHUMPETER, J. Capitalismo, Socialismo e Democracia. São Paulo: Ed. Forense. 1995.

SILVEIRA, S.A. Exclusão Digital: a miséria na era da Informação. São Paulo: Ed. Fundação Perseu Abramo, 2001.

SILVEIRA, S. A. Inclusão digital, software livre e globalização contrahegemônica. In: Seminários Temáticos para a Terceira Conferência Nacional de C,T\&I. 2005.2 Acesso: http://www.softwarelivre.gov.br/softwarelivre/artigos/artigo 02. (em 14 de novembro de 2007).

SILVEIRA, S. A . e CASSINO, J. (org.). Software Livre e Inclusão Digital. São Paulo: Conrad Editora do Brasil, 2003.

SORJ, B. e GUEDES, L.E. Exclusão Digital: problemas conceituais, evidências empíricas e políticas públicas. Novos Estudos. CEBRAP. N.72. junho de 2005.

TAKADASHI, T.(org.). Sociedade da Informação no Brasil - Livro Verde. Ministério da Ciência e Tecnologia. Brasília (DF), 2000.

TREMBLAY, G. La sociedad de la información y la nueva economía: promesas, realidades y faltas de un modelo ideológico. IN: MARQUES DE MELO, J. e SATHLER, L. (org.). Direitos à Comunicação na Sociedade da Informação. São Bernardo do Campo (SP): UMESP (Universidade Metodista de São Paulo), 2005.

WILSON, E. J. Liderança e difusão da Internet: o caso do Brasil. DataGramaZero - Revista de Ciência da Informação. - vol. 1; n.2. Abril 2000.

WORLD BANK. World Development Report - Equity and Development. 2006.

WORLD ECONOMIC FORUM. The Global Information Technology Report. New York/Oxford; Oxford University Press, 2002.

\section{Bibliografia consultada}

BOLAÑO, C. e MATTOS, F. A .M. Conhecimento e Informação na atual reestruturação produtiva: para uma crítica das teorias de gestão do conhecimento. DataGramaZero - Revista de Ciências da Informação. v.5, 
n.3, junho de 2004. Disponível em: http://www.dgz.org.br/jun04/F I art.htm. Acesso em 22 de fevereiro de 2007.

CHESNAIS, F. A Mundialização do Capital. São Paulo: Ed. Xamã, 1996.

DANTAS, M. O Brasil na encruzilhada. Dados e Idéias, n. 100, São Paulo: Gazeta Mercantil Editora, setembro 1986.

. Capitalismo na era das redes: trabalho, informação e valor no ciclo da comunicação produtiva. IN: LASTRES, H. M. M. et ALBAGLI, S. (org.). Informação e Globalização na Era do Conhecimento. Rio de Janeiro: Ed. Campus, 1999.

FIORI, J.L. Brasil no Espaço. Petrópolis (RJ): Ed. Vozes, 2001.

GAO. United States General Accounting Office. Telecommunications: characteristics and choices of internet users. February, 2001.

LOJKINE, J. A revolução informacional. São Paulo: Ed. Cortez, 1995.

LOZADA, M. Política en red y democracia virtual: la cuestión de lo público. In: CULTURA Y TRANSFORMACIONES SOCIALES EN TIEMPOS DE GLOBALIZACIÓN. Venezuela, 2003.

MATTELARD, A. Comment est né le mythe d'Internet. In: Le Monde Diplomatique, pg. 26-32, août, 2000.

MEDEIROS, L.D. e CARVALHO, M.M. Inclusão Digital como perspectiva positiva na sociedade da informação. Pesquisa Brasileira em Ciência da Informação e Biblioteconomia. Vol. 1; n.1. 2006. IBICT.

SCHWARTZ, G. Exclusão digital entra na agenda econômica mundial. Folha de S. Paulo, São Paulo, 18 de janeiro de 2000.

SILVA, M. O. G. Exclusão Digital, uma nova forma de analfabetismo em um novo milênio. conomiaNet. $002 . \quad$ cesso: http://www.economiabr.net/colunas/silva/exclusaodigital.html (em 14 de novembro de 2007). 